\title{
Thinking About People: Contributions of a Typological Alternative to Associationistic and Dimensional Models of Person Perception
}

\author{
Craig A. Anderson \\ University of Missouri-Columbia
}

\author{
Constantine Sedikides \\ University of Wisconsin-Madison
}

\begin{abstract}
The associationistic view of person perception states that people are perceived in terms of trait covariations. The dimensional view maintains that others are perceived by means of a limited number of dimensions. In contrast, the typological view is that others are perceived in terms of person types, and traits within a given person type have a unique interactive relation. In Experiment 1 , associationistic, dimensional, and typological representations of implicit personality theories were empirically derived. The derived stimuli were used in Experiment 2, which examined the effects of person type membership on impression priming and perceived trait belongingness, controlling for associationistic and dimensional factors. As expected, results validated the unique contribution of a typological approach to person perception. Implications of the present findings for the implicit personality theory, stereotype, and person memory literatures are discussed.
\end{abstract}

People constitute important categories of objects. It is of no surprise, then, that thinking about people is such a pervasive phenomenon. We routinely form impressions of other people's personalities, make predictions about their behavior, wonder about their intentions, and evaluate their performance outcomes. In this article, we are concerned with the issue of how we think about, perceive, or cognitively represent other people.

\section{How Do People Think About People?}

There are at least three general views that speak to this issue: The associationistic, the dimensional, and the typological view. ${ }^{1}$

\section{Associationistic and Dimensional Views}

The simplest view, the associationistic, is that people think about others in terms of trait covariations. Expectations about a target person's standing on some unknown trait (e.g., shyness) are derived from beliefs about the correlations of that trait with known traits (e.g., outgoingness, aloofness). More formally, Trait A is expected to accurately describe a person who has Traits B, $\mathrm{C}$, and $\mathrm{D}$ to the extent that $\mathrm{A}$ is believed to correlate positively with $\mathrm{B}, \mathrm{C}$, and $\mathrm{D}$. The expectation for a given unknown trait depends on the perceived relations between that trait and all

We thank the participants in the Nags Head Conference on Social Cognition, especially Dave Schneider, for their helpful suggestions. We also thank Rob Nosofsky and the anonymous reviewers for their perceptive comments on drafts of this article and Phil Wood for his expert advice on multidimensional scaling and cluster analysis. The help of Mary Finch, Deborah Weaver, and Lee Metzler in conducting this research is gratefully acknowledged.

Correspondence concerning this article should be addressed to either Craig A. Anderson at the Department of Psychology, University of Missouri, Columbia, Missouri 65211, or to Constantine Sedikides at the Psychology Department, University of Wisconsin, 1202 West Johnson Street, Madison, Wisconsin 53706. traits that are believed to be present in the target person. Although perceived trait covariations can be operationalized in several different ways, the most straightforward (in our view) is simply the Pearson product-moment correlation.

The dimensional view maintains that the structure of social thinking is dimensional. Trait relations, trait inferences, or our implicit personality theories (IPTs, e.g., Schneider, 1973) about others can be described using a small number of underlying dimensions. That is, people do not think about others at the microscopic level of individual trait covariations; rather, they think about others in terms of a few more global dimensions. Expectations about a target person's unknown traits depend upon the distance in multidimensional space between each unknown trait and the known traits of that person. If the known traits are low on the social evaluation dimension and low on the potency dimension, the expectation that shyness provides an accurate description of the person will be fairly high because shyness falls in about the same multidimensional space. The dimensional view is commonly operationalized by factor analytic or multidimensional scaling (MDS) procedures (e.g., Passini \& Norman, 1966; Rosenberg \& Sedlak, 1972). Although dimensional solutions are typically derived from trait correlation matrixes, the dimensional approach to person perception assumes that people think at the more global level of personality dimensions.

Two to five orthogonal dimensions have been used to describe people's thinking about others. Work by Rosenberg and his colleagues, for example (Kim \& Rosenberg, 1980; Rosenberg, 1976; Rosenberg \& Sedlak, 1972) has demonstrated that the most important dimension is an evaluative one, followed by a dynamism dimension (the fusion of activity and potency, in

\footnotetext{
${ }^{1}$ Other more specific approaches to social thinking include prototype models, exemplar models, multiple-feature-set models, multipleprototype models, and multiple-exemplar models (see J. R. Anderson, 1980; J. R. Anderson, Kline, \& Beasley, 1979; Homa, 1984; and Linville, Salovey, \& Fischer, 1986, for reviews).
} 
the terminology of Osgood, Suci, \& Tannenbaum, 1957). Furthermore, the evaluative dimension can be split into two different versions, one concerned with social aspects and the other concerned with intellectual ones. On the other hand, work by other personality researchers (e.g., Digman \& TakemotoChock, 1981; Goldberg, 1981; McCrae \& Costa, 1985; Tupes \& Christal, 1958, 1961) has described the underlying structure of social thinking in terms of five dimensions. For example, McCrae and Costa (1987) uncovered the following five dimensions: neuroticism, extraversion, openness, agreeableness versus antagonism, and conscientiousness versus undirectedness. ${ }^{2}$

\section{Typological View}

The typological view postulates that people think of others in terms of person types. Such person types may be described in many ways, such as exemplars (e.g., Hintzman, 1986; Medin \& Shaffer, 1978; Smith \& Zarate, in press), multiple-feature sets (e.g., Estes, 1986; Hayes-Roth \& Hayes-Roth, 1977; Linville et al., 1986), or prototypes (e.g., Andersen \& Klatzky, 1987; Brewer, Dull, \& Lui, 1981; Cantor \& Mischel, 1977; Posner \& Keele, 1968; Reed, 1972). Though these positions make different predictions in many contexts, such distinctions are not important here. Regardless of the specific structure, the typological view is that we come to hold beliefs about how certain sets of traits tend to cluster, or go together. Each set of clustering traits constitutes a person type. For instance, people are classified as extraverts or introverts (Cantor \& Mischel, 1977), as mature or immature (Schneider \& Blankmeyer, 1983), as depressed or lonely (Horowitz, French, \& Anderson, 1982). As a further example, clinical diagnoses are well described by a person-type approach (Cantor, Smith, French, \& Mezzich, 1980).

Typically, person types have been constructed on the basis of the relations among within-set traits. For instance, Cantor and Mischel (1977; see also Cantor et al., 1980; Markus, 1977) had subjects rate a large number of traits for the degree of their relatedness to the person types extravert and introvert. Traits rated as being highly related to extravert were seen as members of the extravert person type, those rated as highly related to introvert were seen as members of the introvert person type. Another way to operationalize the typological view would be by applying cluster analysis to trait ratings. Clusters would constitute the person types.

\section{Contrasting the Three Views of Person Perception}

The three person perception views make different assumptions regarding the nature of social (i.e., person) categories. The associationistic view states that social categories can be well described by simple trait covariation. The dimensional view holds that social categories can be well described by dimensions regardless of the internal structure of the categories. In contrast, the typological view maintains that traits composing a social category have an integrity or internal connectedness that differs from trait relations between categories. Recent research on concept and classification learning (e.g., Carey, 1982; Jacoby \& Brooks, 1984; Medin \& Smith, 1984; Murphy \& Medin, 1985; Oden, 1987; Reed, 1972; Smith \& Medin, 1981; Whittlesea, 1987 ) is compatible with the view that categories are not neces- sarily dense regions of highly correlated attributes and that categorization can best be understood by seeing features in a given set in an interactive manner. Thus, the central question is, does a typological or person-type approach yield anything unique to our understanding of how people think about other people? Or can a dimensional or associationistic approach account for people's perceptions of others?

Although a casual look at the prototype literature appears to provide ample evidence of effects uniquely related to person types, closer inspection reveals that the uniqueness question has not been resolved. To be sure, several researchers have addressed this question (e.g., Andersen \& Klatzky, 1987; Powell \& Juhnke, 1983) and obtained promising results. However, in the vast majority of work in this area, definitions of what constitutes prototypes (or more generally person types) do not include clauses demanding differentiation from or control for dimensional or associationistic models of IPT. Thus, although past prototype research has appropriately defined prototypes for the goals of that research, it provides little evidence that a persontype concept unique from dimensional or associationistic factors was in operation. For instance, extravert and introvert prototypes may each consist of traits perceived by subjects as being highly correlated (the associationistic definition) or of traits located relatively close to each other in subjects' perceived multidimensional trait space.

But are person types simply groups of highly correlated traits? Are they simply clumps of traits located close to each other in multidimensional space? We maintain that they are not. In our Gestalt-like view, person types mean considerably more to the perceiver than their average intercorrelation or their average distance in multidimensional space. To be sure, the traits included in a given person type will tend to be highly correlated with each other and will tend to be dimensionally close to each other. However, some person types may contain one or more trait members that are only moderately correlated (in perceivers' eyes) with the other members. Indeed, we expect that for some person types there will exist nonmember traits having higher average correlations with the members than one or more of the member traits. The most extreme versions of such person types are some stereotypes. Several racial, ethnic, and occupational stereotypes contain traits commonly seen as only weakly or even negatively interrelated, in both associationistic and dimensional terms. Blacks are seen as gifted (musically, athletically) and lazy. Jewish mothers are seen as caring and interfering. Businessmen are seen as good citizens and ruthless. In sum, our intuitions about person types as well as the labeling and categorization literatures (e.g., Schneider \& Blankmeyer, 1983) suggest that person types are Gestalt-like in that their effects are not entirely predictable from a simple aggregation (average correlation or dimensional location) of information about constituent trait members; the whole is more than the sum of the parts.

\footnotetext{
${ }^{2}$ Additional dimensional approaches include information integration theory (N. H. Anderson, 1962) and work on what constitutes central versus peripheral traits in impression formation (Wishner, 1960; Zanna \& Hamilton, 1972).
} 


\section{Testing the Unique Contributions of a Typological Approach}

The goal of the present research was to explore the possibility that a typological view adds to our understanding of social thinking above and beyond the associationistic and dimensional views. Note that we are not pitting the three views against each other in some all-or-none fashion, in part because the three views are not wholly incompatible.

The basic strategy was to examine the effects of person-type membership (member versus nonmember) after controlling for dimensional and associationistic parameters. If membership in a person type had some effect (e.g., on belongingness ratings) even when these parameters were controlled, then we could say with confidence that person types are unique Gestalts, not merely clumps of spatially or correlationally related traits.

Rather than using the most extreme kind of person types, the stereotypes, we decided to look at more subtle and general person types. One reason for this decision was to provide a more convincing demonstration; if it works for subtle person types, it has to be a powerful effect. A second reason was methodologically motivated. We wanted to generate the person types from the same data base used to get the associationistic and the dimensional control information. For reasons to be discussed later in detail, the methods used to generate this information precluded the possibility of getting extreme stereotypes.

Several design features needed to be present to provide an adequate test of our hypothesis that person-type-membership status contributes something beyond the associationistic and dimensional views. First, a set of general person types needed to be generated. Second, a criterion task was needed, in which the effects of type membership (member or not) could be assessed. Third, the effects of person-type membership needed to be assessed with associationistic and dimensional location parameters controlled.

Controlling for associationistic and dimensional parameters required several more features. The data base giving rise to the associationistic and dimensional measures needed to be large, representative, and reliable. Furthermore, the dimensional solution needed to provide a good fit, and the individual trait relations needed to be reliable. Finally, a large and representative set of traits needed to be used initially, to guarantee that several person types having the necessary characteristics (i.e., having nonmember trait alternatives that meet the associationistic and dimensional location control criteria) would be generated.

\section{Overview}

\section{Stage 1}

In Experiment 1, a large group of people described target persons by rating them on 108 different traits (the person description data). Another group of subjects rated each trait on 15 different dimensions, such as warm-cold and interesting-boring (the trait description data). A trait intercorrelation matrix was computed from the person description data. The simple intercorrelations were later used to control for associationistic relations. We performed an MDS analysis of the correlation matrix to get the information needed to control for dimen- sional location relations. The trait description data were used to help identify the dimensions in the MDS analysis and provide further evidence that IPTs were being accurately assessed. The trait correlation matrix was further subjected to a hierarchical cluster analysis. This procedure was used to identify person types, here defined as trait clusters.

For MDS and cluster analyses, the correlation matrix was treated as a similarity matrix, defined in the broad sense used in the scaling tradition. There are, of course, alternative ways of generating similarity data for a set of stimuli. Each procedure has different meanings, strengths, and weaknesses. One obvious possibility would be to have subjects rate pairs of traits on similarity of meaning. A methodological problem with similarity ratings is the number of trait pairs created by 108 traits5,778 such pairs. A more serious problem with the similarity of meaning procedure is conceptual. IPTs and stereotypes contain some features that are seen as going together very strongly but that are not seen as being very similar in meaning. To take an extreme example from standard racial stereotypes, many people see the features "being Oriental" and "being industrious" as going together, but a semantic similarity rating task would not result in these features going together. Our study dealt only with traits, but the same logic applied. We needed to allow traits that differed in meaning to be grouped together in the final representation (be it dimensional or typological), if people saw them as co-occurring, or we would not have been examining IPTs. Our trait correlation procedure produced a type of co-occurrence matrix of similarity data, wherein high correlations (e.g., .7) indicated trait pairs that people saw as going together and low correlations (e.g., -.7 ) indicated trait pairs that people saw as seldom co-occurring. Obviously, trait pairs seen as being very similar in meaning also would yield high correlations. The key advantage to our procedure was that it allowed semantically dissimilar trait pairs to be spatially close if they were seen as co-occurring. Also note that because the trait intercorrelations were computed across subjects, one may best view the correlation matrix as a cultural co-occurrence matrix, rather than an individual-subject-based one.

\section{Stage 2}

All of the data and analyses described in the previous section were used to create stimuli for the critical Experiment 2. For each cluster, the weakest member was deleted; the remaining core members were presented to subjects with impression formation instructions. Strong nonmember traits for a given cluster were selected if they had higher associations with and closer distances to the cluster impression set traits than did the weakest member of the cluster. After forming the impression, subjects wrote out brief descriptions of the target person and then rated the weakest member and the strong nonmember traits on scales designed to assess subjects' perceptions of how well each trait fit with the impression set. The associationistic and the dimensional models would predict that the strong nonmember traits would be perceived as better fitting with the cluster core traits than would the weakest cluster member, whereas the typological model would predict the opposite. 


\section{Experiment 1}

\section{Method}

\section{Part 1: Person Description}

Subjects. Subjects were 197 undergraduates fulfilling introductory psychology course requirements. Subjects were run in groups of 8 to 46 persons.

Procedure. Subjects were told that they were participating in a study of how people perceived the personalities of other people and that their task was to bring in mind and describe two targets on 108 traits. Most traits $(100)$ were chosen on the basis of meaningfulness and likability from N. H. Anderson's (1968) trait list, with all ranges of likability evenly represented. Eight more were added for historical reasons.

Each subject rated two targets. Half of the subjects rated a target they knew very well and liked and a target they knew very well and disliked. The remaining half of the subjects rated a target they had met only once or twice but they thought they would like and a target they had met only once or twice but they thought they would dislike. The main purpose of these manipulations was to ensure a wide range of person descriptions. Subjects rated how characteristic each trait was of the target they described on 5-point scales labeled not at all characteristic (1), slightly characteristic (2), moderately characteristic (3), strongly characteristic (4), and extremely characteristic (5).

Each trait was presented on a separate card; trait cards for each subject were shuffled and enclosed in an envelope. Each subject received two envelopes, corresponding to the two targets the subject was supposed to rate. The order of the two envelopes was randomized for each subject, and instructions were typed on the envelope. Subjects took the first envelope, noted what kind of target they were to describe, brought the target in mind, wrote the target's age, gender, and relation to them on the envelope, and made a liking rating on a 7-point scale, ranging from extremely dislike (1) to extremely like (7). Then, subjects removed the trait cards and rated the target on each trait by writing a number ( 1 through 5$)$ on the trait card. After finishing the first target, subjects put all the trait cards back in the envelope, sealed it, and proceeded to the next envelope. On completion of the task, subjects designated their gender and age. Then they were debriefed, were thanked for their participation, and were excused.

\section{Part 2: Trait Description}

Subjects. Fifty undergraduate students participated in groups ranging in size from 8 to 25 persons and received credit toward an introductory psychology course requirement.

Procedure. Each subject was provided with an envelope containing 108 cards on which were printed one of the traits used in Part 1. Each subject was also provided with 108 sheets of paper. Each sheet contained 155 -point rating scales, corresponding to 15 dimensions. The 15 dimensions were pleasant-unpleasant, like-dislike, bad-good, activepassive, extraverted-introverted, impulsive-inhibited, dominant-submissive, dependent-independent, friendly-unfriendly, cold-warm, open-minded-close-minded, important-unimportant, interestingboring, intellectual capabilities (high-low), social skills (high-low). For each of the 108 traits, subjects imagined a target who could be best described by that trait. Then, subjects rated the imagined target on the 15 dimensions. Subjects were thanked and then were debriefed and excused.

\section{Resulls and Discussion}

\section{Person Description Results}

Three hundred ninety-four people were described with 108 trait ratings by the 197 subjects in Part 1 . The trait ratings were correlated across the 394 person descriptions. As previously noted, the resulting correlation matrix was essentially a culturally perceived co-occurrence similarity matrix. A strong positive correlation between 2 traits indicated that targets rated high on 1 trait tended to be rated high on the other and that targets rated low on 1 trait tended to be rated low on the other. A strong negative correlation between 2 traits indicated that targets rated high on 1 trait tended to be rated low on the other trait and vice versa. Correlations close to zero indicated that ratings on 1 trait were not predictive of ratings on the other.

These correlations were converted to dissimilarities and subjected to a series of MDS analyses, using the ALSCAL-4 program through SAS (Young \& Lewyckyj, 1979; note that MDS analyses of the similarities data produced practically identical results). Nonmetric MDS was used in the Kruskal/Shepard tradition (Kruskal, 1964; Shepard, 1962a, 1962b, 1972). Nonmetric MDS computes intertrait distances on an ordinal scale and derives Euclidean dimensions by an iterative search procedure. Figure 1 contains two fit indexes for each of the six obtained solutions. The $R^{2}$ (RSQ) index is the proportion of variance of the disparities that is accounted for by the solution. Stress (Kruskal's Stress Formula 1) is the square root of a normalized residual sum of squares and is therefore better thought of as a "badness-of-fit" measure, with larger scores indicating a worse fit.

The results of these analyses revealed three main points. First, a two-dimensional (2-D) solution was deemed most appropriate, although a three-dimensional (3-D) solution was also reasonable. Second, the 2-D solution fit the data quite well, $\mathrm{RSQ}=.95$, stress $=.121$. Third, inspection of the dimensional locations of various traits suggested that the two dimensions consisted of a general evaluation dimension and a dimension related to dynamism or activity. ${ }^{3}$ Table 1 lists selected extreme traits for both dimensions. We will return to the labeling issue shortly.

\section{Trait Description Results}

The 108 traits were rated on each of 15 marker dimensions by the 50 subjects in Part 2. Means across the 50 subjects were computed for each trait on each marker dimension. The resulting 108 (traits) by 15 (dimensions) matrix of average ratings was subjected to a principal-components factor analysis. Figure 2 is a scree plot of the eigenvalues. As can be seen in Figure 2, the data were best described by two factors, according to an eigenvalue-greater-than-one criterion.

The factors were only slightly correlated, indicating that an orthogonal solution was acceptable. Inspection of the factor loadings suggested that the two dimensions consisted of a general evaluative one and one related to dynamism, as in the MDS

\footnotetext{
${ }^{3}$ We also conducted a series of INDSCAL analyses using multiple matrices created by various experimental and classification variables. Specifically, we looked for differences in importance of dimensions as a function of sex of subject, sex of target, familiarity of target, and liking of target. We used the analysis of angular variation procedure suggested by Schiffman, Reynolds, and Young (1981) to perform significance tests on the dimension weights from INDSCAL. No consistent differences were found.
} 


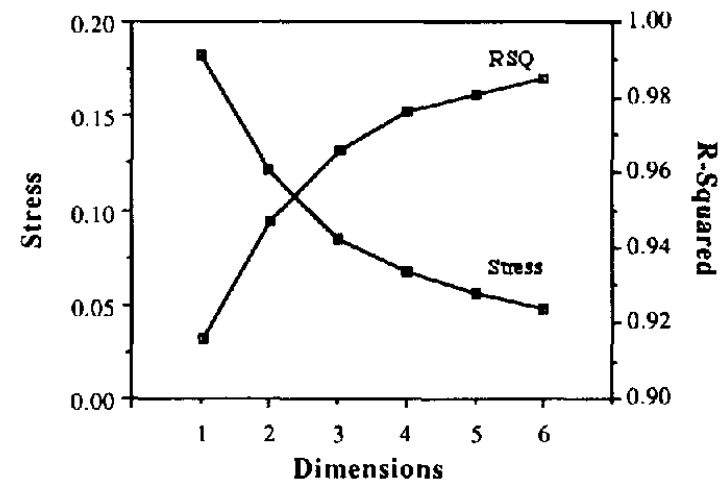

Figure 1. Stress and $R^{2}$ (RSQ) measures of fit of one- through six-dimension multidimensional scaling solutions.

results on the person description data of Part 1. Table 2 contains the rotated factor loadings. Subjects who rated people that were imagined to have one specific trait apparently produced essentially the same structural relations among traits as did subjects who rated real people (cf. Passini \& Norman, 1966).

\section{Comparison of Person Description and Trait-Rating Results}

The main purpose of gathering the trait-rating data was to aid in labeling the MDS results. Although there are many ways to do this with the data at hand, the clarity and consistency of results from several quite different analyses allowed presentation of fairly simple procedures.

The basic unit of analysis consisted of the trait set. For each of the 108 traits, we had two MDS dimension scores (from the 2-D solution) and 15 average marker dimension ratings. Our first comparison of the person description results with the marker

Table 1

Selected Traits With Extreme Locations on Dimension I or Dimension 2 of the Two-Dimension Multidimensional Scaling Solution

\begin{tabular}{|c|c|c|c|c|c|}
\hline \multicolumn{3}{|c|}{ Extreme on Dimension 1} & \multicolumn{3}{|c|}{ Extreme on Dimension 2} \\
\hline Selected Trait & $\underset{1}{\text { Dim. }}$ & $\underset{2}{\text { Dim. }}$ & Selected Trait & $\underset{1}{\text { Dim. }}$ & $\begin{array}{c}\text { Dim. } \\
2\end{array}$ \\
\hline Pleasant & 1.81 & 0.02 & Quiet & 0.79 & 1.32 \\
\hline Honest & 1.79 & 0.11 & Shy & 0.64 & 1.31 \\
\hline Thoughtful & 1.79 & 0.15 & Dependent & 0 & 1.14 \\
\hline Trustful & 1.79 & 0.14 & Gullible & -0.76 & 0.98 \\
\hline Helpful & 1.78 & 0.08 & Worrier & -0.66 & 0.95 \\
\hline Polite & 1.77 & 0.17 & Conformist & -0.78 & 0.94 \\
\hline Competent & 1.66 & -0.22 & Aggressive & -0.68 & -0.98 \\
\hline Intelligent & 1.63 & -0.30 & Impulsive & -0.43 & -0.99 \\
\hline Unkind & -1.43 & -0.11 & Talkative & 0 & -1.01 \\
\hline Insincere & -1.44 & -0.05 & Noncomforming & 0.06 & -1.03 \\
\hline Narrow-minded & -1.44 & 0.11 & Frank & 0.38 & -1.09 \\
\hline Liar & -1.45 & 0.11 & Daring & 0.36 & -1.25 \\
\hline Unreliable & -1.45 & -0.06 & & & \\
\hline Dishonest & -1.46 & -0.04 & & & \\
\hline
\end{tabular}

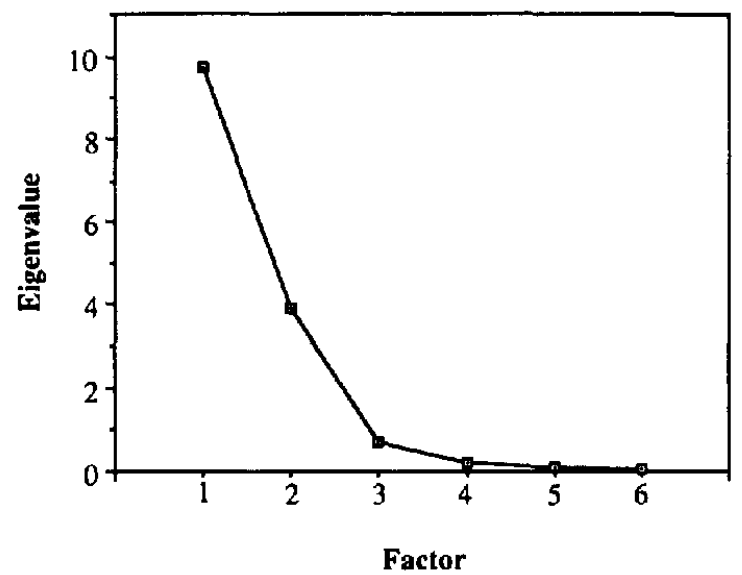

Figure 2. Scree plot for factor analysis of ratings of 108 traits on 15 dimensions.

dimension results consisted of correlating MDS dimension scores with the average marker dimension ratings across the 108 traits. Table 3 presents these results separately for the 10 marker dimensions that loaded most heavily on Factor 1 and the 5 that loaded most heavily on Factor 2.

For our second comparison, we computed factor scores for the 108 traits, which were based on the factor analysis of the marker dimension trait ratings. We then correlated these factor scores with the MDS dimension scores derived from the person descriptions. As seemed inevitable from the pattern revealed in Table 3, Factor 1 correlated quite highly with Dimension $1(r=$ $.91), t(106)=23.2, p<.001$, and Factor 2 correlated quite highly with Dimension $2(r=.86), t(106)=17.3, p<.001$. Furthermore, Factor 1 did not correlate with Dimension $2(r=-.04)$ and Factor 2 did not correlate with Dimension $1(r=-.12)$. These analyses quite clearly show that the two MDS dimensions are well described as general evaluation and dynamism.

Overall these results indicate that the data met the basic re-

Table 2

Rotated Factor Pattern on the I5 Marker Scales

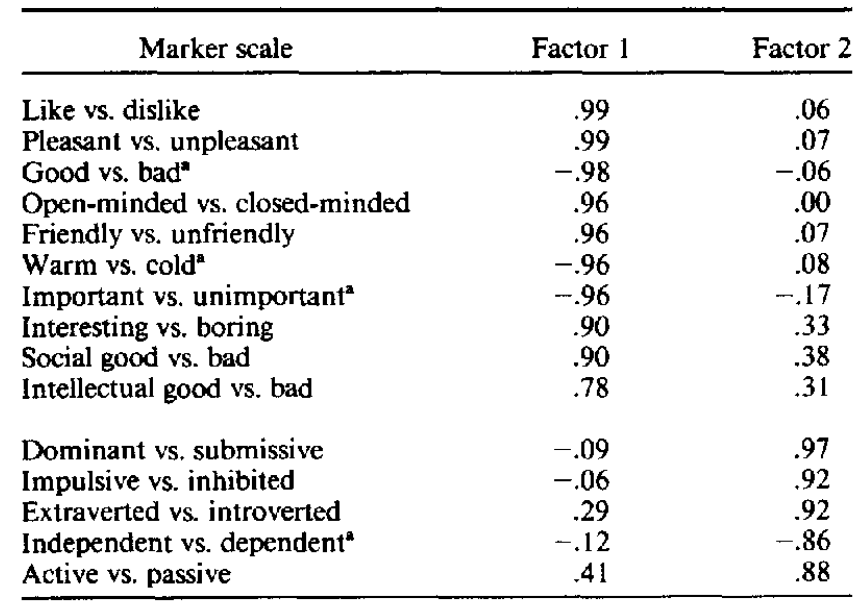

These scales were reversed in the presentation format to subjects. 
Table 3

Correlations Between the Trait-Rating Marker Scales

and the Dimensions From the Two-Dimensional

Multidimensional Scaling Solution

\begin{tabular}{ccc}
\hline Marker scale & Dimension 1 & Dimension 2 \\
\hline
\end{tabular}

Scales with primary loading on Factor 1

Good vs. bad

Like vs. dislike

Important vs. unimportant

Pleasant vs. unpleasant

Intellectual good vs. bad

Social good vs. bad

Open-minded vs. closed-minded

Friendly vs. unfriendly

Interesting vs. boring

Warm vs. cold

Scales with primary loading on Factor 2

Dominant vs. submissive

Impulsive vs. inhibited

Extraverted vs. introverted

Independent vs. dependent

Active vs. passive

\begin{tabular}{rr}
.07 & -.82 \\
-.05 & -.81 \\
.35 & -.80 \\
.28 & -.78 \\
.46 & -.74 \\
\hline
\end{tabular}

quirements for testing the unique contribution of a typological approach. The person descriptions were generated by a large number of subjects (197), described a large number of targets (394), and described a wide range of targets (e.g., familiar or unfamiliar, liked or disliked). These features produced trait correlations that are representative and reliable. Furthermore, these descriptions were well fit by a dimensional model. Thus, if meaningful person types can be derived from the same person description data, we should be able to control for dimensional and associationistic factors in a test of the potential unique contributions of the typological approach.

\section{Cluster Analysis on the Person Description Data}

A hierarchical cluster analysis using an average linkage rule was performed on the trait correlation matrix (Johnson, 1967; Ward, 1963). Clustering algorithms differ in several respects. Some begin with all items in one large cluster and then iteratively split the set into more and smaller clusters until each item is its own cluster, on the basis of within-cluster proximities. Other algorithms begin with each item as its own cluster and iteratively combine items (and item sets) having the largest similarity scores until all are in one large cluster. Although cluster analyses in general have the potential of uncovering existing person types (cf. Powell \& Juhnke, 1983), the latter type of algorithm most closely matched our intuitions concerning person types. Thus, the BMDPIM program was used; the input matrix was defined as a similarity matrix. (Defining the input as correlations produced the same main clusters.)

Interpreting cluster analysis results, just as interpreting MDS and factor analysis results, is a subjective process. Three simple rules were used in our analysis: (a) A cluster must contain at least 4 traits and no more than 10, (b) intracluster similarity scores must be 70 or greater (this roughly corresponded to an average correlation among cluster items of .40), (c) when a large cluster meets the first two criteria but can be subdivided into two smaller (and tighter) clusters that also meet the first two criteria, the two smaller clusters should be used. Although somewhat arbitrary, such rules prevent a haphazard approach to selection of trait clusters. Furthermore, the ultimate criterion for the validity of any cluster solution is its ability to produce theoretically meaningful results in different contexts (cf. Whittlesea, 1987). These rules resulted in derived clusters that met the needs of our experiment, accurately represented people's understanding of what constitutes a person type, and provided a reasonable interpretation of the results.

Eleven clusters emerged from this analysis, containing from 4 to 7 traits each. A total of 56 traits appeared in the clusters; the remaining 52 traits did not meet the criteria for inclusion in a person type cluster. The 11 clusters and their trait members are listed in the Appendix. Inspection of these clusters revealed person types that are intuitively reasonable; one can recognize all the types as being part of his or her own implicit personality theories and many of the types as fitting perceptions of particular people one knows. Thus, the cluster analysis apparently recovered common or familiar person types. Note that the MDS results did not yield such insights into the structure of person descriptions.

Further insight may be gained by inspection of Figure 3. In this figure, the clusters are presented in a tree diagram. The points of intersection between lines indicate the level of similarity at which sets of traits were joined into a larger cluster by the cluster analysis. Similarity is a BMDPIM rescaled variable ranging from minimal similarity $(0)$ to maximal similarity (100). In the present data, the similarity corresponds fairly closely to $(r+1) /(02)$. Thus, a similarity score of 0 corresponds (closely) to an average intercorrelation of -1 ; a similarity score of 50 corresponds to an average intercorrelation of 0 ; and 100 corresponds to 1 . Overall, good traits and bad traits joined at a negative correlation level. This matches the MDS results rather well in that a very strong general evaluative dimension emerged.

The 11 named clusters are vertically positioned, so that the similarity scores correspond to intracluster similarity. For exam-

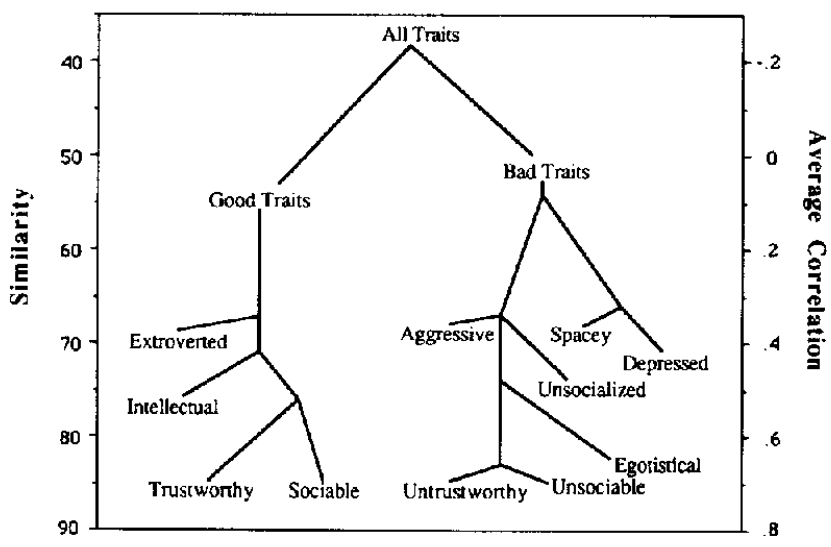

Figure 3. Cluster analysis organized by within-cluster similarity. 
ple, trustworthy is a tight cluster, having a similarity score of 86 (average intracluster $r$ of about .70). Conversely, spacey is a fairly loose cluster (similarity score of 70, average intracluster $r$ of about .40 ).

To get a better feel for the person types and their interrelations, we computed their dimensional locations using the MDS results and plotted the clusters in 2-D space. Figure 4 contains this plot. The clusters varied primarily along the evaluation dimension, although their variation along the dynamism dimension is also both apparent and meaningful. One does think of aggressive people as being more active than spacey ones, for instance.

We also plotted cluster items in both 2-D and 3-D space. As expected, we could find no plots that would satisfactorily separate traits into the derived clusters. Figure 5 contains the 2-D plot for the traits contained in four of the clusters. As can be seen, this MDS solution does not clearly distinguish the clusters found by the clustering algorithm.

In sum, the cluster analysis produced results that corresponded quite closely to the MDS results, but it provided additional information as well. Specifically, the cluster analysis recovered meaningful person types that could not be identified by the MDS results. Hence, these results support the position that person types contribute to perceptions of other people over and beyond the associationistic and dimensional approaches.

However, we recognize that claiming support on the basis of these results is premature at best. Our failure to see as much in the 2-D and 3-D plots as in the cluster results could reflect our own biases or perceptual shortcomings. Furthermore, one might argue that higher dimensional MDS solutions would produce equivalent information if only we could visualize more than 3 dimensions. Such an argument ignores the fact that either 2 or 3 dimensions fit the MDS results extremely well, but the argument nonetheless has merit. What is needed is further

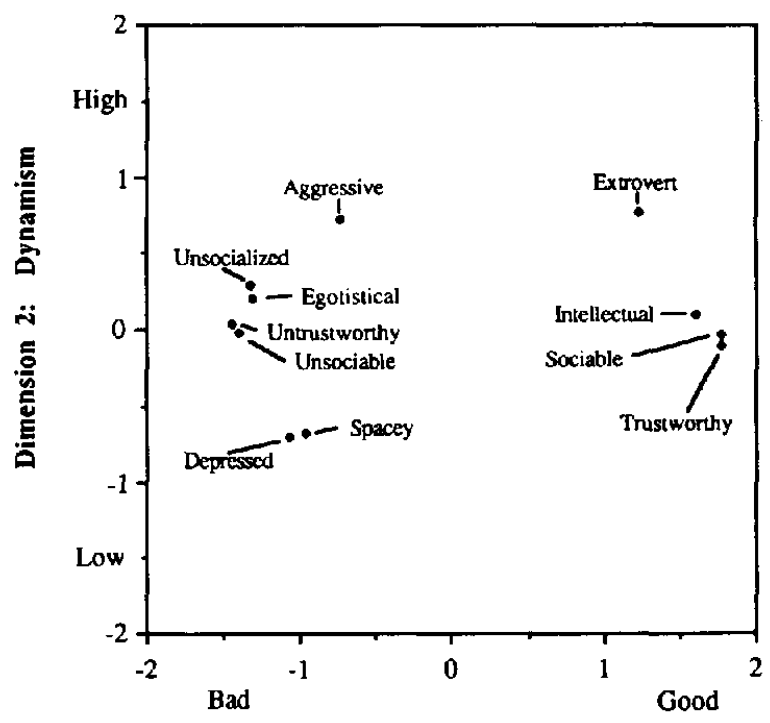

Dimension 1: Evaluation

Figure 4. Plot of clusters in two-dimensional multidimensional scaling space.

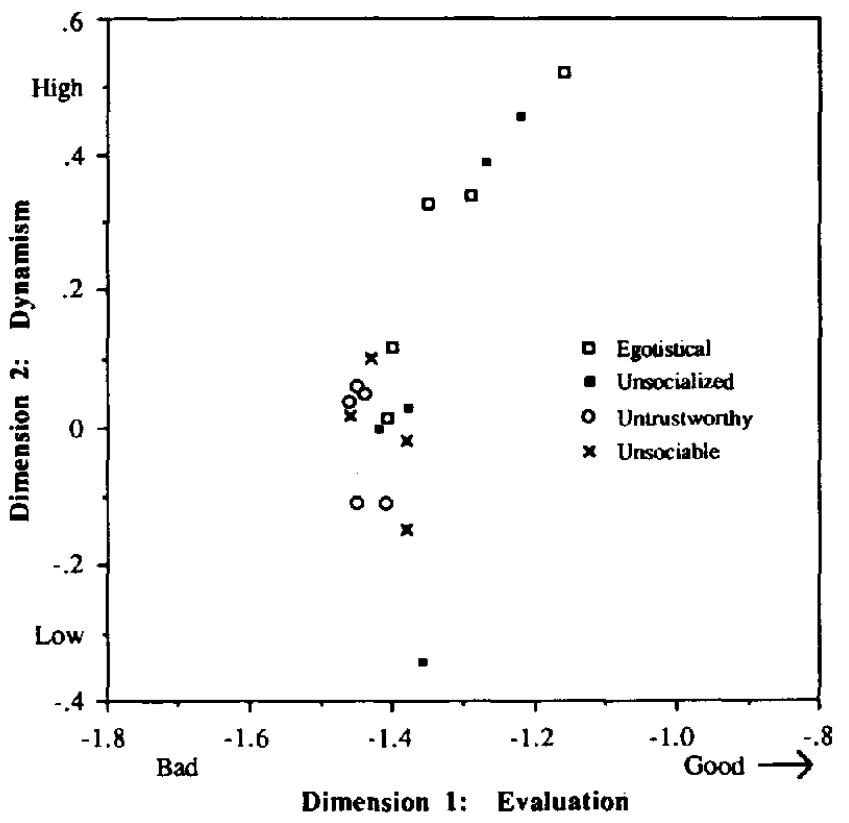

Figure 5. Plot of member traits of four negative clusters in two-dimensional multidimensional scaling space.

validation that the derived person types contribute to person perception in a unique way, in relation to the dimensional factors. Before presenting such evidence, though, a brief excursion into how the methodological differences between MDS and cluster analysis relate to our theoretical points is necessary.

\section{Cluster Analysis and Person Types}

To validate the unique contributions of a typological approach, we must show that cluster membership (versus nonmembership) predicts subjects' perceptions of people(e.g., memories or judgments) even when associationistic and dimensional factors have been equated. To do this, we must identify strong nonmember traits, which are at least as closely related (from an associationistic or a dimensional perspective) to a given cluster as the worst fitting member of the cluster. Such strong nonmembers were relatively rare, because the cluster and the MDS analyses used the same trait intercorrelations as the input measures of similarity.

However, we expected to find some strong nonmembers for some of the clusters because of differences in the analytic techniques that are reflective of theoretical differences between an associationistic, a dimensional, and a typological approach. The major difference between these approaches in the present context concerns the computational rules used. Consider the early stages of the cluster analysis procedure, in which Traits A and B have already been clustered on the basis of their high correlation. Now consider Trait $\mathrm{C}$. The associationistic computation of C's nearness (or belongingness) to $A B$ is simply the average of C's correlations with A and B. This measure, though, does not take into account C's relation to D, E, and F and their relations to $\mathrm{A}$ and $\mathrm{B}$. In contrast, the MDS dimensional computation of C's belongingness to $\mathrm{AB}$ does take into account other 
trait relations to some extent. That is, each trait's location in MDS space has been determined in a way that minimizes overall stress, a measure of how well the MDS configuration reproduces the total input matrix. Belongingness is thus simply average MDS distance from $\mathbf{A B}$.

But the dimensional approach does not fully account for possible relations between $C$ on the one hand and D, E, and F on the other. Cluster analysis and the typological approach do. In particular, when $C$ is more closely related to $D, E$, and $F$ than to $A B$, it will be clustered with DEF rather than $A B$ regardless of how highly correlated or how close it is to AB. Another trait, $\mathrm{X}$, that is as close to $A B$ as $C$ is, will be clustered with $A B$ if it is not more closely related to other clusters. Thus, in our view, the cluster analysis correctly identifies cluster members both on the basis of how close they are to each other and on how far they are from other potential clusters.

Note that we do not claim that the cluster analysis procedures depict underlying psychological processes. However, we do think that the special interrelation among members of a person type precludes (to some extent) similar interrelations with more than one person type; a trait seldom can be a key feature of more than one type. The cluster analysis procedure described earlier does pick up on this feature of the typological approach to person perception. ${ }^{4}$

Our typological model thus predicts that with a sufficiently large and representative number of traits and person descriptions, one should be able to find person types (clusters of traits) for which there exist nonmember traits having (a) higher average intercorrelations with the cluster members than does one of the members and (b) smaller MDS distances from the cluster members than one of the members. Most important, the typological view predicts that such strong nonmember traits will be perceived as having poorer fits with the person type than the weak member traits having equivalent or poorer relations (i.e., intercorrelations or MDS distances) with the person type. The associationistic and dimensional views predict the opposite.

The existence of acceptable strong nonmember traits was examined by comparing the average correlations and distances of person type members (within each of the 11 derived person types) to the average correlations and distance of all nonmembers. First, for each person type, the weakest member was identified as the member with the lowest average intercorrelation with the other members. The other members constituted the core members. (We applied the same procedure using MDS distances. The procedures yielded the same weakest member in 10 of 11 cases.) Next, all nonmember traits were compared with the weakest member; those that had higher average intercorrelations with the core members than did the weakest member were defined to be acceptable strong nonmembers.

Eight of the clusters had at least one strong nonmember. There were 40 such traits. These eight clusters along with their respective strong nonmembers are presented in the Appendix. Also noted in the table are which items of the clusters make up their person type cores and which are the weakest members.

When the further restriction was added that strong nonmembers also be closer in 2-D MDS space than the weakest member traits, the number of strong nonmembers dropped but was still a usable 20. Several different definitions of strong nonmembers were used in Experiment 2. For now, note that these results confirm the existence of strong nonmembers and provide the basic stimuli for the more critical validation study to follow.

\section{Experiment 2}

\section{Method}

\section{Subjects}

The subjects were 28 undergraduate students participating to satisfy a psychology course option. Sex of subject yielded no significant effects and so is not discussed.

\section{Materials, Procedure, and Design}

Core, weakest member, and strong nonmember traits were available for eight person types, derived from the results of Experiment 1 . The cluster member having the lowest average intercorrelation with other members was the weakest member trait. All nonmember traits having a higher average correlation with the core traits than the weakest member were designated strong nonmember traits. There were from one to nine strong nonmembers for the eight clusters.

Subjects were informed that the experiment tested how people think about other people. Their task was to consider a set of traits, imagine what a person with those traits would be like, write a short description of that hypothetical person, and make several judgments regarding that person. All stimuli were presented in booklet form. For each person type, subjects first read the core traits and formed an impression of a person having those traits. Next, subjects were instructed to write a description of the hypothetical person they had imagined as having the core traits. The two purposes of this task were to ensure that subjects formed an impression that was based on the core traits and to provide data allowing assessment of whether the weakest member traits were more likely to be mentioned spontaneously than the strong nonmember traits. After completing this impression formation and description task, subjects examined a list of strong nonmember traits along with the weakest member trait. The strong nonmember and the weakest member traits were rated on a belonging scale in terms of whether each particular trait belonged to the imagined person. The belonging scale ranged from does not belong (1) through might belong (5) to very likely belongs ( 9 ). A fter the belonging task was a conditional probability task. Subjects again were given the strong nonmembers and the weakest member trait for the cluster, as well as the core items. For each of the strong nonmember and the weakest member traits, subjects estimated the percentage of adults having the trait, given that they had the core traits. Subjects were subsequently debriefed, then they were thanked for their participation and were excused.

All subjects responded to the same eight person-type stimuli, in different random orders. In addition, the presentation order of strong nonmember and weakest members was randomized; three such orders were used. Presentation order yielded no reliable effect; therefore, it was not included in the reported analyses. The overall design was thus

\footnotetext{
${ }^{4}$ Our cluster analysis approach is only one way of identifying person types that are unique from dimensional approaches. We see it as a conservative one, given the restrictiveness of reliance on the same type of similarity data used in dimensional approaches. For example, stereotypes containing contradictory traits (caring and interfering) cannot be identified using our approach because over a large set of target people, such traits will be seen as negatively correlated. Future research on the typological approach may profitably use other methods to identify person types, as long as comparable data on dimensional issues are also considered.
} 
completely within-subjects and had two factors: person type (the eight clusters) and member status (weakest member versus strong nonmember). For cases in which more than one strong nonmember was available, the average of the strong nonmembers was used.

Our main hypotheses concerned the effects of membership status (weakest member versus strong nonmember) on the target traits. Briefly, the person-type approach predicts that on average, weakest member traits will yield higher belonging ratings and higher conditional probability judgments and will be generated more frequently in the written impressions than will the strong nonmember traits. As we had no interest in differences between the different person types, only the results of the member status independent variable were reported.

\section{Results and Discussion}

The three dependent variables were spontaneous trait ascriptions, belonging ratings, and percentage ratings. Several sets of analyses were carried out to test our basic hypothesis that weakest members would be seen as better fits than strong nonmembers. Separate analyses were carried out for different criteria of what constituted a strong nonmember. The most inclusive definition was the one described earlier: all nonmember traits having higher average intercorrelations with the core than the corresponding weakest member. We called this the 0-D (zerodimension) analysis, because none of the MDS results were used in this definition. In essence, the 0-D analysis tests the typological view (i.e., the weakest members) versus the associationistic view. More restrictive definitions were used to test several MDS versions. The 2-D analysis was based on strong nonmembers that were both more highly correlated with the core traits and closer in 2-D MDS space to the core traits than the corresponding weakest traits. This definition resulted in fewer acceptable strong nonmembers and clusters. Indeed, only five of the clusters had at least one strong nonmember.

Two higher dimensional analyses were also carried out to ensure that our findings were not artifacts of an incomplete MDS solution, as discussed in the Results section of Experiment 1. Specifically, one could argue that a more complete (i.e., higher dimensionality) MDS solution is needed and that use of a more complete solution would eliminate any typological model superiority. Of course, this argument presupposes a relatively poor fit of the 2-D MDS solution. As pointed out earlier, though, the 2-D solution was deemed best, and it provided a very good fit $(\mathrm{RSQ}=.95$, stress $=.121)$. Also note that as the dimensionality is increased, the MDS solution becomes more like the input correlation matrix, so that in the extreme case, in which there are $k-1$ dimensions (where $k$ is the number of variables), the MDS solution recovers the correlation matrix.

The empirical answer to this possible problem was to analyze the current experiment with several dimensional definitions of strong nonmembers. Therefore, 3-D and 6-D analyses were conducted in addition to the 2-D analysis. The 3-D solution was used because the results of Experiment 1 suggested that either a 2-D or a 3-D solution was appropriate. The 6-D solution was used because we wanted to be sure that the incomplete-solution alternative explanation would be adequately addressed and six dimensions was the maximum our MDS package (SAS ALSCAL-4) could produce.

\section{Spontaneous Trait Ascriptions}

For each person type, subjects first formed an impression by imagining a person having the person-type core traits. Subjects then wrote a brief description of the imagined person. The written descriptions were examined; all trait inferences were recorded and compared with the list of strong nonmembers and the weakest member trait for the appropriate person type. A gist coding scheme was used in this analysis. Thus, a statement such as "this person would steal from his own mother" was coded as an instantiation of the trait dishonest. ${ }^{5}$

We predicted that the weakest member traits would, on average, be more likely to be generated spontaneously by impression formation than would the strong nonmember traits. The associationistic and dimensional approaches predict just the opposite, because the strong nonmembers are more highly correlated with and closer in MDS space to the core.

For all the definitions of what constitutes strong nonmember traits, the weakest members were significantly more likely to be spontaneously generated than were their corresponding strong nonmembers. For the 0-D analysis, for instance, the average proportion of spontaneous generation of weakest members, averaged across the eight person types, was. 22 ; the corresponding average for strong nonmembers was. 08 . This difference was highly significant, $F(1,27)=24.30, p<.001$. Furthermore, as can be seen in Table 4 , this effect occurred regardless of which MDS dimensional criterion was used.

\section{Belonging Ratings}

Subjects rated the weakest member and the strong nonmember traits on the degree to which each belonged to a person described by the core impression-set traits. Table 4 contains the means of the weakest member and the strong nonmember trait ratings, for each of the four definitions of strong nonmember traits. As predicted, the weakest member traits received higher belonging ratings than the strong nonmember traits regardless of which MDS criteria were used, all $F \mathrm{~s}(1,27)>15, p \mathrm{~s}<.001$.

\section{Percentage Estimates}

The final dependent measure consisted of subjects' estimates of the percentage of people who had each of the strong nonmember and the weakest member traits, given that they had the core impression-set traits. For each of the four definitions of strong nonmember traits, Table 4 contains the means of the weakest member and the strong nonmember trait ratings. Once again the predicted results were obtained. Subjects gave higher conditional probability estimates for the weakest member traits than for the corresponding strong nonmembers for each of the MDS defined criteria, all $F \mathrm{~s}(1,27)>8, p \mathrm{~s}<.01$.

Remember that the 0 -D analyses tested our typological ap-

\footnotetext{
${ }^{5}$ A strict coding, which was based on the target traits and synonyms, was also carried out. The major effect of strict coding was that the frequencies of both weakest member and strong nonmember traits dropped considerably. However, the same pattern was obtained as with the gist coding, and the results still were statistically significant ( $p$ s $<$ $.05)$.
} 
Table 4

Means and $F$ Ratios for Weakest Member and Strong Nonmember Traits for Spontaneous Generation, Belonging Ratings, and Conditional Probability Estimates

\begin{tabular}{|c|c|c|c|c|}
\hline \multirow[b]{2}{*}{ Dependent variable } & \multicolumn{4}{|c|}{ Definition of strong nonmember traits ${ }^{\mathrm{a}}$} \\
\hline & $0-\mathrm{D}$ & 2-D & $3-\mathrm{D}$ & $6-\mathrm{D}$ \\
\hline \multirow{2}{*}{\multicolumn{5}{|c|}{ Spontaneous generation }} \\
\hline & & & & \\
\hline Weakest members & .22 & .19 & .28 & .25 \\
\hline Strong nonmembers & .08 & .06 & .09 & .08 \\
\hline$F$ for difference & $24.30^{* * *}$ & $12.32^{* *}$ & $21.90^{* * *}$ & $19.71^{* * * *}$ \\
\hline \multicolumn{5}{|l|}{ Belonging ratings } \\
\hline \multicolumn{5}{|l|}{$M$} \\
\hline Weakest members & 7.26 & 7.05 & 7.45 & 7.29 \\
\hline Strong nonmembers & 6.45 & 6.49 & 6.85 & 6.60 \\
\hline$F$ for difference & $38.81^{* * *}$ & $15.29^{* * *}$ & $18.66^{* * *}$ & $29.70^{* * *}$ \\
\hline \multicolumn{5}{|c|}{ Conditional probability estimate } \\
\hline \multicolumn{5}{|l|}{$M$} \\
\hline Weakest members & 24.6 & 25.1 & 26.9 & 25.8 \\
\hline Strong nonmembers & 22.0 & 22.6 & 24.6 & 23.1 \\
\hline$F$ for difference & $13.62^{* * * *}$ & $8.76^{* *}$ & $6.30^{*}$ & $14.82^{* * *}$ \\
\hline
\end{tabular}

Note. $\mathrm{D}=$ dimensional. $d f=1,27$.

a For all definitions, each strong nonmember had a higher average correlation with the core traits than did the corresponding weakest member. For $0-D$, this was the only criterion. For the 2-D, 3-D, and 6-D definitions, each strong nonmember also was closer in 2-D, 3-D, or 6-D MDS space (respectively) than the corresponding weakest member.

${ }^{*} p<.05 .^{* *} p<.01 .^{* * *} p<.001$.

proach while controlling for the associationist position. The 2and 3-D analyses tested the ty pological approach while controlling for the appropriate dimensional aspects. Finally, the 6-D analyses tested the typological approach against the incomplete solution argument. The fact that all results were as predicted provides strong evidence that a typological approach to person perception adds significantly to the associationistic and dimensional approaches.

\section{An Alternative Explanation}

One might speculate that the obtained effects resulted from a few misclassified strong nonmember traits, because of normal variation in sample correlations. For example, several of the strong nonmembers may actually correlate less highly with the target core traits than the relevant weakest member trait.

By using all available strong nonmembers, we have already dealt with this potential problem to some extent. This is because there are two main types of classification errors possible: Some strong nonmembers may actually have lower (rather than higher) correlations with the target core traits than the relevant weakest member; some strong nonmembers may actually be stronger members of the person-type cluster than the weakest member. The first classification error could help our hypothesis; the other works against it. By using all identified strong nonmembers and combining results across person types, our procedure would tend to average out whatever classification errors might exist. However, one type of misclassification error may occur with greater frequency than the other. If the first classification error is relatively more likely, then our procedures could overestimate the pawer of cluster membership.

Thus, we also addressed the alternative explanation empiri- cally. Our first approach was to see if there was a systematic relation between the core correlations of strong nonmembers and the mean judgments made by subjects in Experiment 2. The alternative explanation predicts strongly positive correlations. For each cluster having more than two strong nonmembers, the correlation between the strong nonmembers' average core correlations and the mean judgments of belonging was calculated. In no case did the correlation reach significance, $p s>.10$. Most of the correlations were slightly positive, as one might expect, but one was fairly negative. ${ }^{6}$ We also correlated these scores across all 40 strong nonmembers (rather than within target cluster). This correlation was negative, but not significantly so $(p>.10)$.

Our second empirical approach was to eliminate the most extreme strong nonmembers-that is, those most likely to be misclassified. The current strong nonmembers most likely to be truly misclassified cluster members were those with the largest discrepancy between their core correlation and their corresponding weakest member core correlation. (Actually, $r$ squared was used.) At the other end of this distribution of discrepancy scores were strong nonmembers that perhaps should not have been included because in truth their core correlation was lower than that of the weakest member. These would be the strong nonmembers with the smallest discrepancy in relation to the weakest member.

To examine what would happen when the most likely misclassified strong nonmembers were eliminated, we analyzed the belonging ratings after deleting the strong nonmembers in the top and bottom $10 \%$ of the discrepancy distribution. The

\footnotetext{
${ }^{6} \mathrm{~A}$ sign test on these correlations also was nonsignificant $(p>.3)$.
} 
results were quite clear. All the basic effects remained for all the models $(0-\mathrm{D}, 2-\mathrm{D}$, etc), all $\mathrm{ps}<.001$. One could maintain that we should have eliminated only the strong nonmembers that theoretically may have inappropriately helped the hypothesis in our original analyses. Analyses eliminating only the lowest $20 \%$ did not eliminate the effects, all $p s<.01$.

A third empirical approach to this alternative explanation involved dividing the original sample of person descriptions (from Experiment 1 ) into two subsamples. We decided to do this by sex of subject, though for our present purposes a random split would also have served. We next computed the trait correlation matrix for each subsample and examined the weakest member and strong nonmember trait correlations with their target core traits. To avoid capitalizing on any possible selection artifact, we used the same weakest member traits as in the original analyses. To remain in the subsequent analysis, a strong nonmember trait had to have a higher average correlation with the core traits than the relevant weakest member for each of the three samples (male, female, and whole sample). As expected, this conservative procedure did reduce the number of strong nonmember traits and the number of clusters having at least one acceptable strong nonmember trait. However, the smallest stimulus sample still had 10 strong nonmember traits in four clusters (the 6-D definition). Note that the original analyses produced a minimum of 19 strong nonmember traits (3-D), and a minimum of five clusters (2-D). Analyses of the belonging ratings from Experiment 2, using this new reduced set of strong nonmember traits, yielded clear results. All of the effects $(0-D$, $2-\mathrm{D}, 3-\mathrm{D}, 6-\mathrm{D})$ remained ( $p \mathrm{~s}<.002$ ). Indeed, two of the four analyses yielded stronger effects than the original analyses. Thus, the misclassification alternative hypothesis is not tenable.

\section{General Discussion}

\section{Summary of Findings}

The goals of the present article were (a) to demonstrate that the typological approach (operationalized by a clustering algorithm) could lead to the identification of meaningful sets of traits that the associationistic view (operationalized in terms of trait intercorrelations) and the dimensional view (operationalized by an MDS algorithm) could not and (b) to validate this position with independent data from an impression formation experiment.

Our large sample of person descriptions, which included a large range of targets and subjects and which was based on a large sample of traits, was well modeled by a 2-D MDS solution. The derived dimensions (general evaluation and dynamism) corresponded well with previous findings in this area. Furthermore, an independent group of subjects who provided ratings on 15 marker dimensions for the same set of traits produced the same 2-D implicit personality theory. Again, this finding provides a strong conceptual replication of past research.

Despite the high-quality fit obtained by the MDS analysis, a subsequent hierarchical cluster analysis provided additional insights into how people think about other people. Clearly recognizable person types emerged from the cluster analysis. Close examination of the derived person types resulted in the identification of strong nonmember traits that were more closely re- lated (in associationistic and dimensional terms) to the cluster core than the weakest cluster member.

Most important, though, were the results of Experiment 2, in which the effects of cluster membership status (weakest member versus strong nonmember) on several dependent variables were assessed, after controls for associationistic and dimensional factors were in place. Membership status had a clear effect on the spontaneous generation of related traits, on perceived belonging of traits, and on conditional probability estimates. In all cases, members were seen as better fits than nonmembers, even though nonmembers were more closely related by associationistic and dimensional criteria. Experiment 2 validated the position that traits within person types have a structure of their own. That is, person types are more than clumps of traits that are close to each other associationistically or multidimensionally.

\section{Structure of IPT: Dimensional vs. Typological}

Note that this research was designed to examine the possibility that person types contain additional information, relative to associationistic and dimensional models. The results clearly demonstrated this to be the case. However, the present results do not conclusively demonstrate that people think about others in terms of types or that IPTs are structurally represented as person-type categories. IPTs may be represented both dimensionally and typologically in memory. It may be possible to devise methods whereby dimensional representations yield information on person judgments that is superior to typological representations. What this work has done is to clearly demonstrate that a typological approach provides important advances in understanding the development of trait expectancies by means of initial impression sets. In essence, the present work is an empirical validation of the natural groupings of person stimuli as person types. Most important, this research demonstrates the need for work in IPT to go beyond dimensional approaches.

\section{On the Structure of Person Types}

Much of past research on prototypes, person types, and IPT in the social domain has failed to demonstrate that person types are anything more than groups of highly associated traits. Our reading of this literature suggests that these theoreticians believe such types to be more than the sum of their parts (i.e., their perceived similarity). The present research confirms this intuition of many past scholars. However, we have not solved the problem of describing just what that extra something is. Several possibilities come to mind.

Research in a variety of areas has demonstrated the importance of causal relations in everyday thinking. For instance, story comprehension seems intimately tied to goals and motives, which provide reasons for actions, and to particular action scripts or scenarios, in which events at one point in time enable or cause particular events at a later time (e.g., Black, Galambos, \& Read, 1984). The power of attribution theory in a wide variety of domains also attests to the ubiquity of causal thinking. Attributional processes are often spontaneously activated (e.g., C. A. Anderson, 1983; Hastie, 1984; Winter \& Ule- 
man, 1984; Wong \& Weiner, 1981) and may be either fairly automatic or quite explicitly controlled. Other research has shown that causal links between events are quite strong, resistant to change, and frequently used in judging the relatedness of events (C. A. Anderson, New, \& Speer, 1985; C. A. Anderson \& Sechler, 1986; Pennington \& Hastic, 1986; Read, 1987; Tversky \& Kahneman, 1982). Person types may differ from similar groupings of traits in the perceived causal relations among the traits. Traits in the same person type may be seen as being causally related in some way, possibly as reflections of the same underlying causal disposition.

A second possible explanation of the integrity of person types has to do with the perceived distribution of people. Person types may be sets of traits that perceivers believe to co-occur with unusual frequency. In MDS terms, this may be represented as unusually dense concentrations of people in multidimensional space, or as local maxima. It is not immediately clear to us how one could derive such a configuration and relate it to traits in a person-type approach, though we suggest one possibility in the following section. Note that this explanation is not incompatible with the first.

A third possibility derives from an exemplar view of person categorization (e.g., Medin \& Shaffer, 1978). If person types are represented by one or a few exemplars (real or composites), then the special linkage between traits within a type or cluster may simply be that they belong to the same person exemplar.

Finally, one could take a Gibsonian (Gibson, 1966) view of person types and postulate that information about person types exists in the social stimuli, that person types are thus perceived directly, and that the integrity need not be broken down or analyzed further. We are uncomfortable with such a view, because we believe that further analysis is possible. Person types can be described more completely by studying relations among parts. Indeed, our first suggestion about the perceived causal relations among traits focuses precisely on elemental relations.

\section{Stereotypes}

We view person types as subtle but real versions of stereotypes. One interesting feature of many stereotypes is that they contain features that in other contexts would seem contradictory. Of particular interest are stereotypes containing both evaluatively positive and negative features. For instance, Jewish mothers are seen as caring and interfering; businesspersons are seen as good citizens and ruthless. Such person types, though, cannot be identified by the cluster analysis procedures used in the present article, because generally positive traits and generally negative traits are separated early in any cluster analysis of trait intercorrelations. S. M. Andersen and Klatzky's (1987) distinction between social stereotypes and trait categories captures some of this within-person inconsistency; their methods for investigating this distinction may prove useful in addressing the typological/dimensional issue.

A second interesting feature concerns potential negative consequences of the causal nature of the special person-type links hypothesized earlier. Certainly, much of the adverse impact of negative racial stereotypes at the individual level occurs because of an implicit belief that expected negative features asso- ciated with the race are caused by an underlying factor associated with the race. Such a causal belief increases the resistance to contradictory information and also suggests that attempts to modify the negative features (i.e., treat the symptoms) will necessarily result in failure. From this standpoint, the stereotype-based perception of outgroup members as all alike is a causal one on the part of the stereotype-holder.

Alternatively, as suggested in the prior section, the integrity of person types may derive from unusually dense areas in the multidimensional space of perceivers' IPTs. Thus, one possible technique for recovering person types that contain evaluatively contradictory traits may be to do cluster analyses of the described persons, rather than traits (cf. Rosenberg, 1976). Then one would need to identify the distinguishing features of the derived clusters. Such research is beyond the scope of this article, but we feel that if the methodological problems can be solved, improved understanding of stereotypes and person types will result.

\section{Person Memory}

Our findings of unique person-type effects and our approach to describing similarity among traits have implications for research in person memory. The relation between trait (or behavior) consistency and memory for traits (or behaviors) has received much attention (Hastie, 1980; Hastie \& Kumar, 1979; Srull, 1981; Wyer \& Gordon, 1982). Many advances have been made recently (e.g., Bargh \& Thein, 1985; Devine \& Ostrom, 1988; Erber \& Fiske, 1984; Srull, Lichtenstein, \& Rothbart, 1985 ), yet key questions concerning the definition of consistency remain. We propose that one definition of trait consistency be the correlation between traits (cf. Devine \& Ostrom, 1988). The correlation matrix from our person description data essentially describes which traits people expect to co-occur with which other traits. Trait pairs with strong positive correlations are consistent; those with strong negative correlations are inconsistent; those with essentially zero correlations are unrelated.

A somewhat different definition of consistency would be based on trait distances in the multidimensional space. Knowing the dimensional locations of traits (in two, three, or six dimensions for instance), one could compute a distance matrix which parallels the correlation matrix. Trait pairs that are close to each other are consistent; those that are far apart are inconsistent; those that are an intermediate distance apart are unrelated. $^{\text {? }}$

These definitions have both methodological and theoretical implications. Methodologically, they allow one to create stimulus sets with known characteristics. One could systematically vary the consistency of impression sets, hold constant the relation of the target traits to the impression sets, and observe the results. Similarly, one could hold constant the consistency of the impression sets but vary the target consistency.

Theoretically, use of these definitions leads to a host of ques-

\footnotetext{
${ }^{7}$ The raw correlation matrix $(108 \times 108)$ and the two-, three-, and six-dimensional multidimensional scaling results are available from Craig A. Anderson and Constantine Sedikides.
} 
tions regarding person memory. For instance, what is the relation between trait consistency and memory? Does this relation depend on factors that encourage or inhibit causal thinking, studying, or attempts at impression formation? Does the trait consistency-memory relation differ as a function of the definition of consistency used? Perhaps the distance definition works better than the correlation version. If so, what does this reveal about the underlying cognitive processes? Finally, perhaps distance along one dimension (e.g., the evaluative one) is more important than distance along the other.

Of course, we also expect cluster membership to affect memory and cognitive process variables, such as attention. That is, even after controlling for various dimensional factors, member status should still influence the cognitive processes involved in person perception.

\section{Concluding Remarks}

Typological models of person perception add to our understanding of social thinking. People do think of others in terms of person types; these person types are not completely describable in dimensional terms.

Using different methodologies, Powell and Juhnke (1983) reached similar conclusions. Subjects examined a set of traits and sorted them into groupings reflective of real people. These same traits were rated for their similarities to each other. The results showed that a cluster analysis of similarity ratings of traits was more accurate in reproducing direct groupings of traits than either factor analysis or MDS of the same similarity ratings. Our work went beyond Powell and Juhnke's work in independently validating the integrity of person types through an impression formation experiment. Nevertheless, although either set of studies alone may be only moderately convincing, our work in combination with the results of Powell and Juhnke demonstrates the need for a typological approach to person perception.

We feel that current information-processing models of person perception can be modified to accommodate the special connectedness of traits belonging to the same person type. As yet, we do not know what connects these types of traits, although we have speculated that a type of perceived causal link exists. Future work in this area should attempt to explicate the links more clearly so that a more complete picture of the person perception process can be drawn.

\section{References}

Andersen, S. M., \& Klatzky, R. L. (1987). Traits and social stereotypes: Levels of categorization in person perception. Journal of Personality and Social Psychology, 53, 235-246.

Anderson, C. A. (1983). Abstract and concrete data in the perseverance of social theories: When weak data lead to unshakeable beliefs. Journal of Experimental Social Psychology, 19, 93-108.

Anderson, C. A., New, B. L., \& Speer, J. R. (1985). Argument availability as a mediator of social theory perseverance. Social Cognition, 3 , 235-249.

Anderson, C. A., \& Sechler, E. S. (1986). Effects of explanation and counterexplanation on the development and use of social theories. Journal of Personality and Social Psychology, 50, 24-34.
Anderson, J. R. (1980). Cognitive psychology and its implications. San Francisco: Freeman.

Anderson, J. R., Kline, P. J., \& Beasley, C. M. (1979). A general learning theory and its application to schema abstraction. In G. H. Bower (Ed), The psychology of learning and motivation (Vol. 13, pp. 277318). San Diego, CA: Academic Press.

Anderson, N. H. (1962). Application of an additive model to impression formation. Science, 138, 817-818.

Anderson, N. H. (1968). Likableness ratings of 555 personality trait words. Journal of Personality and Social Psychology, 9, 272-279.

Bargh, J. A., \& Thein, R. D. (1985). Individual construct accessibility, person memory, and the recall-judgment link: The case of information overload. Journal of Personality and Social Psychology, 49, $1129-1146$.

Black, J. B., Galambos, J. A., \& Read, S. J. (1984). Comprehending stories and social situations. In R. S. Wyer, \& T. K. Srull (Eds.), Handbook of social cognition (Vol. 3, pp. 45-86). Hillsdale, NJ: Erlbaum.

Brewer, M. B., Dull, V., \& Lui, L. (1981). Perceptions of the elderly: Stereotypes as prototypes. Journal of Personality and Social Psychology, 41, 656-670.

Cantor, N., \& Mischel, W. (1977). Traits as prototypes: Effects on recognition memory. Journal of Personality and Social Psychology, 35, $38-48$.

Cantor, N., Smith, E. E., French, R., \& Mezzich, J. (1980). Psychiatric diagnosis as prototype categorization. Journal of Abnormal Psychology, 89, 181-193.

Carey, S. (1982). Conceptual change in childhood . Cambridge, MA: MIT Press.

Devine, P. G., \& Ostrom, T. M. (1988). Dimensional vs. categorical information processing approaches to social knowledge: The case of inconsistency management. In D. Bar-Tal \& A. Kruglanski (Eds.), The social psychology of knowledge (pp. 231-261). Cambridge, England: Cambridge University Press.

Digman, J. M., \& Takemoto-Chock, N. K. (1981). Factors in the natural language of personality: Reanalysis, comparison, and interpretation of six major studies. Multivariate Behavioral Research, 16, 149170.

Erber, R., \& Fiske, S. T. (1984). Outcome dependency and attention to inconsistent information. Journal of Personality and Social Psychology, 47, 709-726.

Estes, W. K. (1986). Array models for category learning. Cognitive PSychology, 18, 500-549.

Gibson, J. J. (1966). The senses considered as perceptual systems. Boston: Houghton Mifflin.

Goldberg, L. R. (1981). Language and individual differences: The search for universals in personality lexicons. In L. Wheeler (Ed.), Review of personality and social psychology (Vol. 1, pp. 203-234). Hillsdale, NJ: Erlbaum.

Hastie, R. (1980). Memory for behavioral information that confirms or contradicts a personality impression. In R. Hastie, T. M. Ostrom, E. B. Ebbesen, R. S. Wyer, Jr., D. L. Hamilton, \& D. E. Carlston (Eds.), Person memory: The cognitive basis of social perception (pp. 1-53). Hillsdale, NJ: Erlbaum.

Hastie, R. (1984). Causes and effects of causal attributions. Journal of Personality and Social Psychology, 46, 44-56.

Hastie, R., \& Kumar, A. P. (1979). Person memory: Personality traits as organizing principles in memory for behaviors. Journal of Personality and Social Psychology, 37, 25-38.

Hayes-Roth, B., \& Hayes-Roth, B. (1977). Concept learning and the recognition and classification of exemplars. Journal of Verbal Learning and Verbal Behavior, 16, 321-338.

Hintzman, D. L. (1986). Schema abstraction in multiple-trace memory models. Psychological Review, 93, 411-428. 
Homa, D. (1984). On the nature of categories. In G. H. Bower(Ed), The Psychology of Learning and Motivation (Vol. 18, pp. 49-94). San Diego, CA: Academic Press.

Horowitz, L. M., French, R., \& Anderson, C. A. (1982). The prototype of loneliness. In L. A. Peplau \& D. PerIman (Eds.), Loneliness: A sourcebook of current theory, research, and therapy (pp. 183-205). New York: Wiley.

Jacoby, L. L., \& Brooks, L. R. (1984). Nonanalytic cognition, memory, perception, and concept learning. In G. H. Bower(Ed), The psychology of learning and motivation (Vol. 18, pp. 1-47). San Diego, CA: Academic Press.

Johnson, S. C. (1967). Hierarchical clustering schemes. Psychometrika, 32, 241-254

Kim, M. P., \& Rosenberg, S. (1980). Comparison of two structural models of implicit personality theory. Journal of Personality and Social Psychology, 38, 375-389.

Kruskal, J. B. (1964). Nonmetric multidimensional scaling: A numerical method. Psychometrika, 29, 115-129.

Linville, P. W., Salovey, P., \& Fischer, G. W. (1986). Stereotyping and perceived distributions of social characteristics: An application to ingroup-outgroup perception. In J. Dovidio \& S. L. Gaertner (Eds.), Prejudice, discrimination, and racism (pp. 165-208). San Diego, CA: Academic Press.

Markus, H. (1977). Self-schemata and processing information about the self. Journal of Personality and Social Psychology; 35, 63-78.

McCrae, R. R., \& Costa, P. T., Jr. (1985). Updating Norman's "adequate taxonomy": Intelligence and personality dimensions in natural language and in questionnaires. Journal of Personality and Social Psychology, 49, 710-721.

McCrae, R. R., \& Costa, P. T., Jr. (1987). Validation of the five-factor model of personality across instruments and observers. Journal of Personality and Social Psychology, 52, 81-90.

Medin, D. L., \& Shaffer, M. M. (1978). Context theory of classification learning. Psychological Review, 85, 207-238.

Medin, D. L., \& Smith, E. E. (1984). Concepts and concept formation. Annual Review of Psychology, 35, 113-138.

Murphy, G. L., Medin, D. L. (1985). The role of theories in conceptual coherence. Psychological Review, 92, 289-316.

Norman, W. T. (1963). Toward an adequate taxonomy of personality attributes: Replicated factor structure in peer nomination personal. ity ratings. Journal of Abnormal and Social Psychology, 66, 574-583.

Oden, G. C. (1987). Concept, knowledge, and thought. Anntual Review of Psychology, 38, 203-227.

Osgood, C. E., Suci, G., \& Tannenbaum, P. M. (1957). The measurement of meaning. Urbana: University of Illinois Press.

Passini, F. T., \& Norman, W. T. (1966). A universal conception of personality structure? Journal of Personality and Social Psychology, 4 $44-49$.

Pennington, N., \& Hastie, R. (1986). Evidence evaluation in complex decision making. Journal of Personality and Social Psychology, 51, 242-258.

Posner, M. I., \& Keele, S. W. (1968). On the genesis of abstract ideas. Journal of Experimental Psychology, 83, 304-308.

Powell, R. S., \& Juhnke, R. G. (1983). Statistical models of implicit personality theory: A comparison. Journal of Personality and Social Psychology. 44, 911-922.

Read, S. J. (1987). Constructing causal scenarios: A knowledge structure approach to causal reasoning. Journal of Personality and Social Psychology. 52, 288-302.

Reed, S. K. (1972). Pattern recognition and categorization. Cognitive Psychology, 3, 382-407.

Rosenberg, S. (1976). New approaches to the analysis of personal constructs in person perception. In A. W. Lanfield (Ed.), Nebraska symposium on motivation (pp. 179-242). Lincoln: University of $\mathrm{Ne}$ braska Press.
Rosenberg, S., \& Sedlak, A. (1972). Structural representations of implicit personality theory. In L. Berkowitz (Ed.), Advances in experimental social psychology (Vol. 6, pp. 235-297). San Diego, CA: Academic Press.

Schiffman, S. S., Reynolds, M. L., \& Young, F. W. (1981). Introduction to multidimensional scaling: Theory, methods, and applications. San Diego, CA: Academic Press.

Schneider, D. J.(1973). Implicit personality theory: A review. Psychological Bulletin, 79, 294-319.

Schneider, D. J., \& Blankmeyer, B. L. (1983). Prototype salience and implicit personality theories. Journal of Personality and Social Psychology, 44, 712-722.

Shepard, R. N. (1962a). The analysis of proximities: I. Multidimensional scaling with an unknown distance function. Psychometrika, $27,125-140$.

Shepard, R. N. (1962b). The analysis of proximities: II. Multidimensional scaling with an unknown distance function. Psychometrika, 27, 219-246.

Shepard, R. N. (1972). A taxonomy of some principal types of data and of multidimensional methods for their analysis. In R. N. Shepard, A. K. Romney, \& S. B. Nerlove (Eds.), Multidimensional scaling: Theory and applications in the behavioral sciences (Vol. 1, pp. 21-47). New York: Seminar Press.

Smith, E. E., \& Medin, D. L. (1981). Categories and concepts. Cambridge, MA: Harvard University Press.

Smith, E. R., \& Zarate, M. A. (in press). Exemplar and prototype use in social categorization. Social Cognition.

Srull, T. K. (1981). Person memory: Some tests of associative storage and retrieval models. Journal of Experimental Psychology: Ihuman Learning and Memory, 7, 440-463.

Srull, T. K., Lichtenstein, M., \& Rothbart, M. (1985). Associative storage and retrieval processes in person memory. Journal of Experimental Psychology: Humun Learning and Memory, 11, 316-345.

Tupes, E. C., \& Christal, R. E. (1958). Stability of personality trait ratings factors obtained under diverse conditions. (United States Air Force WADC Technical Note No. 58-61).

Tupes, E. C., \& Christal, R. E. (1961). Recurrent personality factors based on trait ratings. (United States Air Force ASD Technical Report No. 61-67).

Tversky, A., \& Kahneman, D. (1982). Causal schemas in judgment under uncertainty. In D. Kahneman, P. Slovic, \& A. Tversky (Eds.), Judgment under uncertainty: Heuristics and biases (pp. 117-128). Cambridge, England: Cambridge University Press.

Ward, J. H., Jr. (1963). Hierarchical groupings to optimize an objective function. Journal of the American Statistical Association, 58, 236244.

Whittlesea, B. W. A. (1987). Preservation of specific experiences in the representation of general knowledge. Journal of Experimental Psychology: Learning, Memory, and Cognition, 13, 3-17.

Winter, L., \& Uleman, J. S. (1984). When are social judgments made? Evidence for the spontaneousness of trait inferences. Journal of Personality and Social Psychology, 47, 237-252.

Wishner, J. (1960). Reanalysis of "impressions of personality" Psychological Review, 67, 96-112.

Wong, P. T. P., \& Wciner, B. (1981). When people ask "why" questions, and the heuristics of attributional search. Journal of Personality and Social Psychology, 40, 650-663.

Wyer, R. S., \& Gordon, S. E. (1982). The recall of information about persons and groups. Journal of Experimental Social Psycholog. 18 , $128-164$

Young, F, W., \& Lewyckyj, R. (1979). ALSCAL-4 User's Guide. Chapel Hill, NC: Data Analysis and Theory Associates.

Zanna, M. P., \& Hamilton, D. L. (1972). Attribute dimension and patterns of trait inferences. Psychonomic Science, 27, 353-354. 
Appendix

Empirically Derived Clusters

\begin{tabular}{|c|c|c|c|c|c|}
\hline Cluster & Members & $\begin{array}{c}\text { Strong } \\
\text { nonmembers }\end{array}$ & Cluster & Members & $\begin{array}{c}\text { Strong } \\
\text { nonmembers }\end{array}$ \\
\hline Extraverted & $\begin{array}{l}\text { Ambitious } \\
\text { Enthusiastic } \\
\text { Energetic } \\
\text { Outgoing } \\
\text { Confident }\end{array}$ & $\begin{array}{l}\text { Intelligent } \\
\text { Humorous } \\
\text { Friendly } \\
\text { Warm } \\
\text { Helpful } \\
\text { Pleasant }\end{array}$ & Untrustworthy & $\begin{array}{l}\text { Liar } \\
\text { Distrustful } \\
\text { Dishonest } \\
\text { Insincere } \\
\text { Unreliable }^{\mathrm{a}}\end{array}$ & Unkind \\
\hline \multirow[t]{2}{*}{ Intellectual } & $\begin{array}{l}\text { Intelligent } \\
\text { Efficient } \\
\text { Competent } \\
\text { Studious }^{\mathrm{a}}\end{array}$ & $\begin{array}{l}\text { Trustful } \\
\text { Honest } \\
\text { Reliable } \\
\text { Thoughtful }\end{array}$ & Unsociable & $\begin{array}{l}\text { Cold } \\
\text { Impolite } \\
\text { Unfriendly } \\
\text { Unkind }\end{array}$ & None \\
\hline & & $\begin{array}{l}\text { Helpful } \\
\text { Pleasant } \\
\text { Polite } \\
\text { Attentive }\end{array}$ & Spacey & $\begin{array}{l}\text { Forgetful } \\
\text { Indecisive } \\
\text { Gullible } \\
\text { Absentminded } \\
\text { Clumsy }\end{array}$ & $\begin{array}{l}\text { Inconsistent } \\
\text { Careless } \\
\text { Lazy } \\
\text { Unreliable } \\
\text { Nosy }\end{array}$ \\
\hline \multirow[t]{2}{*}{ Trustworthy } & $\begin{array}{l}\text { Truthful } \\
\text { Honest }\end{array}$ & $\begin{array}{l}\text { Thoughtful } \\
\text { Helpful }\end{array}$ & & Daydreamer ${ }^{a}$ & \\
\hline & $\begin{array}{l}\text { Trustful } \\
\text { Reliable } \\
\text { Dependable }\end{array}$ & & Aggressive & $\begin{array}{l}\text { Domineering } \\
\text { Possessive }^{\mathrm{a}} \\
\text { Aggressive } \\
\text { Dominating }\end{array}$ & $\begin{array}{l}\text { Stubborn } \\
\text { Critical } \\
\text { Short- } \\
\quad \text { tempered }\end{array}$ \\
\hline Sociable & $\begin{array}{l}\text { Thoughtful } \\
\text { Friendly } \\
\text { Warm } \\
\text { Helpful } \\
\text { Pleasant } \\
\text { Cooperative } \\
\text { Polite }\end{array}$ & None & & & $\begin{array}{l}\text { Over-confident } \\
\text { Boastful } \\
\text { Self-centered } \\
\text { Conceited } \\
\text { Unkind } \\
\text { Angry }\end{array}$ \\
\hline \multirow[t]{2}{*}{ Depressed } & $\begin{array}{l}\text { Depressed } \\
\text { Lonely } \\
\text { Gloomy } \\
\text { Pessimistic } \\
\text { Unhappy }\end{array}$ & $\begin{array}{l}\text { Impolite } \\
\text { Boring }\end{array}$ & Egotistical & $\begin{array}{l}\text { Selfish } \\
\text { Conceited } \\
\text { Self-centered } \\
\text { Boastful } \\
\text { Overconfident }\end{array}$ & None \\
\hline & Fearful $^{a}$ & & Unsocialized & $\begin{array}{l}\text { Rebellious } \\
\text { Disobedient } \\
\text { Inconsistent } \\
\text { Careless } \\
\text { Lazy }\end{array}$ & $\begin{array}{l}\text { Liar } \\
\text { Unreliable } \\
\text { Impolite } \\
\text { Selfish } \\
\text { Dishonest } \\
\text { Unkind } \\
\text { Insincere }\end{array}$ \\
\hline
\end{tabular}

Note. Members are traits included in the cluster. Strong nonmembers are nonmember traits having higher average correlations with the core members than do the weakest members.

a Noncore (weakest) members.

Received January 19, 1990

Revision received July 23, 1990

Accepted July 25, 1990 